The correspondence section is a public forum and, as such, is not peer-reviewed. EHP is not responsible for the accuracy, currency, or reliability of personal opinion expressed herein; it is the sole responsibility of the authors. EHP neither endorses nor disputes their published commentary.

\section{EMFs and Childhood Leukemia}

doi: 10.1289/ehp.10217

In their otherwise informative and concise review of the current state of evidence concerning risk factors for acute childhood leukemia, Belson et al. (2007) did not correctly address nonionizing radiation and, in particular, power frequency magnetic fields as a possible risk factor for childhood leukemia. This failure may be due to a widespread misconception about the evidence concerning nonionizing electromagnetic fields (EMFs) as a health hazard. It is also apparent in the Churchill County leukemia cluster study published in the same issue, in which Rubin et al. (2007) investigated a multitude of factors, many with sparse or ambiguous previous evidence of an association with childhood leukemia. Although power frequency magnetic fields have been classified as a possible human carcinogen (group 2B) by the International Agency for Research on Cancer (IARC 2002) and by a National Institute of Environmental Health Sciences (NIEHS) working group (NIEHS 1998), based on the evidence of an association with childhood leukemia, these were apparently not considered by Rubin et al. (2007).

In their review of nonionizing radiation, Belson et al. (2007) inappropriately mixed original research and pooled analyses, further contributing to the prevailing confusion. Both Ahlbom et al. (2000) and Greenland et al. (2000) presented pooled analyses that included the important study of Linet et al. (1997). Hence, it is inappropriate to present results of the latter as an independent source. Almost all epidemiologic studies of residential exposure to power frequency magnetic fields published before 1999 are included in either the pooled analyses of Ahlbom et al. (2000) or Greenland et al. (2000). Only the study of Myers et al. (1990) was not included because authors refused to provide requested data. Although the study of Linet et al. (1997) is often cited as failing to support the hypothesis of an association between residential exposure to magnetic fields and childhood leukemia [it was also cited by Belson et al. (2007)], it actually was one of the most important supporters of an association in the pooled analyses and contributed the greatest number of highly exposed children. Two large and well-conducted studies published after the pooled analyses (Kabuto et al. 2006; Schüz et al. 2001) lend further support to the results of the pooled analyses

of an increased risk from high average levels of magnetic field exposure.

It is also incorrect to characterize the evidence as "some have found a small association ... while others have not ...." First of all, the association is not small, but is comparable or larger than that for all other factors considered by Belson et al. (2007). Second, the evidence is consistent across different continents, study types, measurement methods, and other factors. Of course, there are potential sources of bias, in particular selection bias. However, thorough investigations of these potential biases have rendered it unlikely that they can completely explain the association. Up to now, there is no other risk factor of childhood leukemia that has been as comprehensively studied concerning possible biases and confounding factors.

It is high time that exposure to power frequency EMFs is recognized as a potential risk factor for childhood leukemia and is properly included in the protocols of cluster studies and in epidemiologic studies of other risk factors as a potential confounder.

The author declares he has no competing financial interests.

\section{Michael Kundi \\ Institute of Environmental Health Center for Public Health Medical University of Vienna Vienna, Austria \\ E-mail: michael.kundi@meduniwien.ac.at}

\section{RefERenCes}

Ahlbom A, Day N, Feychting M, Roman E, Skinner, J, Dockerty $\mathrm{J}$, et al. 2000. A pooled analysis of magnetic fields and childhood leukaemia. Br J Cancer 83:692-698.

Belson M, Kingsley B, Holmes A. 2007. Risk factors for acute leukemia in children: a review. Environ Health Perspect 115:138-145; doi:10.1289/ehp.9023 [Online 30 November 2006].

Greenland S, Sheppard AR, Kaune WT, Poole C, Kelsh MA. 2000. A pooled analysis of magnetic fields, wire codes, and childhood leukemia, Childhood-EMF Study Group. Epidemiology 11:624-634.

IARC (International Agency for Research on Cancer). 2002. Non-ionizing radiation, part 1: Static and extremely lowfrequency (ELF) electric and magnetic fields. IARC Monogr Eval Carcinog Risks Hum 80:1-395.

Kabuto M, Nitta H, Yamamoto S, Yamaguchi N, Akiba S, Honda Y, et al. 2006. Childhood leukemia and magnetic fields in Japan: a case-control study of childhood leukemia and residential power-frequency magnetic fields in Japan. Int J Cancer 119: 643-650.

Linet MS, Hatch EE, Kleinerman RA, Robison LL, Kaune WT, Friedman DR, et al. 1997. Residential exposure to magnetic fields and acute lymphoblastic leukemia in children. N Engl J Med 337:1-7.

Myers A, Clayden A, Cartwright RA, Cartwright SC. 1990 Childhood cancer and overhead powerlines: a casecontrol study. Br J Cancer 62:1008-1014.

NIEHS. 1998. Assessment of Health Effects from Exposure to Power-Line Frequency Electric and Magnetic Fields
(Portier C, Wolfe M, eds). NIH publication no. 98-3981. Available: http://www.niehs.nih.gov/emfrapid/html/ WGReport/WorkingGroup.html [accessed 9 July 2007].

Rubin CS, Holmes AK, Belson MG, Jones RL, Flanders WD, Kieszak SM, et al. 2007. Investigating childhood leukemia in Churchill County, Nevada. Environ Health Perspect 115:151-157; doi:10.1289/ehp.9022 [Online 30 November 2006].

Schüz J, Grigat J-P, Brinkmann K, Michaelis J. 2001. Residential magnetic fields as a risk factor for childhood acute leukaemia: results from a German populationbased case-control study. Int J Cancer 91:728-735.

Editor's note: In accordance with journal policy, Belson et al. were asked whether they wanted to respond to this letter, but they chose not to do so.

\section{lonizing Radiation and Childhood Leukemia}

doi: 10.1289/ehp.10080

I read with interest the recent review by Belson et al. (2007) on childhood leukemia, particularly the sections dealing with radiation exposure. Like the authors, I believe that ionizing radiation is strongly associated with childhood acute leukemia. I would like to point out that several critical pieces of information were overlooked; these support stronger and more meaningful conclusions.

Although atomic bomb survivors offer the clearest evidence of leukemia risk after childhood exposures to ionizing radiation, studies of children exposed to fallout in other contexts should not be downplayed. Belson et al. (2007) stated that "radiation exposure secondary to the Chernobyl accident has not been shown to increase the risk of leukemia in children who were exposed after birth ...," but they failed to mention the case-control study of Noshchenko et al. (2002), which found significant increases in childhood and acute leukemias in association with estimated childhood exposures. Children living downwind of the Nevada Test Site have also shown a significant increase in leukemia related to estimated fallout exposure (Stevens et al. 1990).

In utero exposure to ionizing radiation has been a known causal factor for childhood cancer for $>50$ years. Although Belson et al. (2007) stated that the lack of evidence for a childhood leukemia risk among atomic bomb survivors constitutes the "most notable reason for doubt of a true association," they overlooked the reviews of Wakeford and Little (2002, 2003); these authors demonstrated that the highly uncertain atomic bomb survivor data are statistically compatible with the robust set of data found in the Oxford Survey of Childhood Cancers and related X-ray exposure cohorts. There is no valid reason to doubt this association at present. 
The association between preconception paternal irradiation (PPI) and childhood leukemia has always been controversial. Two of the major objections to the "Gardner hypothesis," as Belson et al. (2007) pointed out, have been mixed evidence from studies of radiation-exposed fathers and a lack of positive evidence in the children of the atomic bomb survivors. Regarding the first objection, Belson et al. overlooked the two largest studies of the children of radiation workers. Draper et al. (1997) conducted a UK-wide case-control study of childhood cancers in relation to paternal radiation exposure. This study showed, based on $>13,000$ cases not included in the study of Gardner et al. (1990), that children with leukemia or non-Hodgkin lymphoma were significantly more likely than controls to have fathers who were radiation workers. Dickinson and Parker (2002) conducted a cohort study of $>250,000$ births in Cumbria, England, including the cases of Gardner et al. (1990), and found a significant 2-fold increase in the risk of leukemia and non-Hodgkin lymphoma among the children of radiation workers. These and other studies, taken together, give statistical support to the idea that paternal radiation work is a risk factor for childhood leukemia.

When interpreting the evidence for a PPI effect in atomic bomb survivors, it is important to consider what is known about potential mechanisms. As reviewed by Niwa (2003), Nomura (2003), and others, animal studies have consistently demonstrated that PPI can cause or increase the susceptibility to leukemia in offspring. In addition to fascinating evidence of postconception genomic instability after preconception exposure, many studies suggest that there may a window of sensitivity corresponding to postmeiotic stages of spermatogenesis; in humans, this would mean the few months leading up to conception (Adler 1996). Of the roughly 30,000 children of atomic bomb survivors, only about $2 \%$ were conceived in the 6 months after the bombings. Based on the spontaneous leukemia rate reported by Yoshimoto (1990), the expected number of spontaneous cases in this subcohort would be $<1$, and an excess on the order suggested by the radiation worker studies would not be statistically apparent. For this and other reasons, the atomic bomb survivors may not be an appropriate comparison group.

To summarize, it is not unreasonable to observe that the weight of evidence generated to date supports the idea that preconception, prenatal, and postnatal exposures to ionizing radiation are all risk factors for childhood leukemia.

The author declares he has no competing financial interests.
Abel Russ
George Perkins Marsh Institute
Worcester, Massachusetts
E-mail: abelruss@riseup.net

References

Adler ID. 1996. Comparison of the duration of spermatogenesis between male rodents and humans. Mutat Res 352(1-2):169-172.

Belson M, Kingsley B, Holmes A. 2007. Risk factors for acute leukemia in children: a review. Environ Health Perspect 115:138-145.

Dickinson HO, Parker L. 2002. Leukemia and non-Hodgkin's lymphoma in children of male Sellafield radiation workers. Int J Cancer 99:437-444.

Draper GJ, Little MP, Sorahan T, Kinlen LJ, Bunch KJ, Conquest AJ, et al. 1997. Cancer in the offspring of radiation workers: a record linkage study. BMJ 315(7117):1181-1188

Gardner MJ, Snee MP, Hall AJ, Powell CA, Downes S, Terrell JD. 1990. Results of case-control study of leukemia and lymphoma among young people near Sellafield nuclear plant in West Cumbria. BMJ 300:423-429.

Niwa 0. 2003. Induced genomic instability in irradiated germ cells and in the offspring: reconciling discrepancies among the human and animal studies. Oncogene 22:7078-7086.

Nomura T. 2003. Transgenerational carcinogenesis: induction and transmission of genetic alterations and mechanisms of carcinogenesis. Mutat Res 544(2-3):425-432.

Noshchenko AG, Zamostyan PV, Bondar OY, Drozdova VD. 2002. Radiation-induced leukemia risk among those aged $0-20$ at the time of the Chernobyl accident: a case-control study in the Ukraine. Int J Cancer 99(4):609-618.

Stevens W, Thomas DC, Lyon JL, Till JE, Kerber RA, Simon SL, et al. 1990. Leukemia in Utah and radioactive fallout from the Nevada test site. A case-control study. JAMA 264(5):585-591.

Wakeford R, Little MP. 2002. Childhood cancer after low-level intrauterine exposure to radiation. J Radiol Prot 22(3A):A123-A127.

Wakeford R, Little MP. 2003. Risk coefficients for childhood cancer after intrauterine irradiation: a review. Int J Radiat Biol 79(5):293-309.

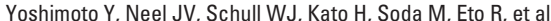
1990. Malignant tumors during the first 2 decades of life in the offspring of atomic bomb survivors. Am J Hum Genet 46(6):1041-1052.

Editor's note: In accordance with journal policy, Belson et al. were asked whether they wanted to respond to this letter, but they chose not to do so.

\section{Methylmercury and the Developing Brain}

doi: 10.1289/ehp.10302

We reported that prenatal exposure to methylmercury causes cognitive impairment in an estimated 316,588 children born in the United States each year, costing this nation $\$ 8.7$ billion annually in lost productivity (Trasande et al. 2005). Each year, this exposure also causes an estimated 1,566 cases of mental retardation (Trasande et al. 2006). The principal (70\%) source of the mercury that enters the bodies of American children is combustion of coal in electricitygenerating plants.

In their reanalysis of our data, Griffiths et al. (2007) made a series of incorrect judgments and poorly considered assumptions, each of which diminishes the import of our findings. We note the following errors in their analysis:

First, Griffiths et al. (2007) incorrectly used a linear model to relate cognitive function to prenatal methylmercury exposure, despite the National Research Council's (NRC) clear finding that a logarithmic model provides a better statistical fit. The NRC, in their examination of the Faroe Islands cohort study, the study on which they place greatest reliance, stated that "[b]ecause these calculations necessitate extrapolating to estimate the mean response at zero exposure level," logarithmic models "lead to lower estimates of the Benchmark Dose (BMD) than linear or K-power models" (NRC 2000, p. 294).

Recent analyses of early childhood lead exposure further corroborate the validity of logarithmic models in representing subclinical dose-response relationships of neurodevelopmental injury (Canfield et al. 2003).

Second, Griffiths et al. (2007) unwisely based their analysis on potentially biased data from the Seychelles cohort study. By contrast, our model (Trasande et al. 2005), like that of the NRC, is based primarily on Faroes data. We chose not to use Seychelles data because of concern that the tests of neurobehavioral function used there were not well validated for a non-American population and therefore may not have been sensitive to detect cognitive impairment (Landrigan and Goldman 2003).

Another major potential source of bias in the Seychelles study, not acknowledged by Griffiths et al. (2007), is that it fails to consider the potentially beneficial nutrients found in the fish-based diet of the Seychelles. These nutrients, omega- 3 fatty acids in particular, may partially offset the toxicity of methylmercury. Indeed, if maternal fish intake is taken into account in the Seychelles cohort, as recently was done, the estimate of methylmercury toxicity increases (BudtzJorgensen et al. 2007).

Griffiths et al. (2007) cited previous meta-analyses of the Faroes, Seychelles, and New Zealand studies by Ryan (2005) in applying IQ decrements of 0.13-0.18 points/ppm hair mercury, but these are likely underestimates, and further invalidate the analysis of Griffiths et al.

Third, in attributing mercury deposition to sources of emission, Griffiths et al. (2007) relied inexplicably and without justification on a mathematical model that posits that only $16 \%$ of deposits are attributable to American sources. They ignored empiric data from the U.S. Environmental Protection Agency (EPA)-sponsored Steubenville study, which found that $80-90 \%$ of mercury emissions deposit within 30-50 miles of the source (U.S. EPA 2007); and from the 
Electric Power Research Institute, which estimated that $30 \%$ of mercury deposits are attributable to American sources (Seigneur et al. 2004).

Fourth, Griffiths et al. (2007) incorrectly assumed that reductions in mercury emissions from power plants do not result in any reduced levels of fish contamination until after 15 years. This is not correct. Reductions in power-plant emissions in 2008 will, in fact, begin immediately to minimize methylmercury body burden among children born to women in 2008, and the degree of reduction will increase further in subsequent years, perhaps through 2038, thus reducing the number of children damaged, the severity of the prenatal brain damage in these children, and the resulting economic burden.

Finally, Griffiths et al. (2007) incorrectly based their estimate of the economic value of a child's social productivity on the 1992 Current Population Survey rather than on the currently available 2005 data set. This miscalculation substantially underestimates the economic impact of methylmercury on the developing brain. Viscusi and Aldy (2004) estimated that this value is currently on the order of \$4-9 million/child, a value far greater than that used by Griffiths et al., and greater even than our estimate.

The authors declare they have no competing financial interests.

Leonardo Trasande Philip J. Landrigan Mount Sinai School of Medicine New York, New York E-mail: leo.trasande@mssm.edu

Clyde B. Schechter

Albert Einstein College of Medicine, Bronx, New York

Richard F. Bopp Rensselaer Polytechnic Institute Troy, New York

\section{REFERENCES}

Budtz-Jorgensen E, Grandjean P, Weihe P. 2007. Separation of risks and benefits of seafood intake. Environ Health Perspect 115:323-327.

Canfield RL, Henderson CR Jr, Cory-Slechta DA, Cox C, Jusko TA, Lanphear BP. 2003. Intellectual impairment in children with blood lead concentrations below 10 microg per deciliter. N Engl J Med 348(16):1517-1526.

Griffiths C, McGartland A, Miller M. 2007. A comparison of the monetized impact of IQ decrements from mercury emissions. Environ Health Perspect 115:841-847.

Landrigan PJ, Goldman L. 2003. Prenatal methylmercury exposure in the Seychelles [Letter]. Lancet 362(9384):666.

NRC (National Research Council). 2000. Toxicological Effects of Methylmercury. Washington, DC:National Academy Press.

Ryan LM. 2005. Effects of Prenatal Methylmercury on Childhood 10: A Synthesis of Three Studies. EPA-HQ-OAR-2002-00566048 and EPA-HO-OAR-2002-0056-6049. Available: http://www.regulations. gov [accessed 20 January 2006]

Seigneur C, Vijayaraghavan K, Lohman K, Karamchandani P, Scott C. 2004. Global source attributions for mercury deposition in the United States. Environ Sci Technol 38(2):555-569.
Trasande L, Schechter C, Haynes KA, Landrigan PJ. 2006. Mental retardation and prenatal methylmercury toxicity. Am J Ind Med 49:153-158.

Trasande L, Schechter C, Landrigan PJ. 2005. Public health and economic consequences of environmental methylmercury toxicity to the developing brain. Environ Health Perspect 113:590-596.

U.S. EPA. 2006. Evaluation Report. Monitoring Needed to Assess Impact of EPA's Clean Air Mercury Rule on Potential Hotspots. Report No. 2006-P-00025. Available http://www.epa.gov/oig/reports/2006/20060515-2006-P00025. pdf [accessed 29 January 2007.

Viscusi WK, Aldy JE. 2004. The Value of a Statistical Life: A Critical Review of Market Estimates Throughout the World. NBER Working Paper 9487. Available http://www. nber.org/papers/w9487 [accessed 2 July 2004].

\section{Methylmercury and the Brain: Griffiths et al. Respond}

\section{doi: 10.1289/ehp.10302R}

In our review of the article by Trasande et al. (2005), we used their published linear model to evaluate the monetized impact of IQ decrements associated with prenatal mercury exposure to methylmercury ( $\mathrm{MeHg}$ ) under different assumptions (Griffiths et al. 2007). First, we used a corrected dose-response slope to address the error that the authors made in the conversion of the relationship between cord blood and neurodevelopment effects. We then introduced the assumptions that the U.S. Environmental Protection Agency (EPA) used in its Clean Air Mercury Rule (CAMR). Introducing the U.S. EPA assumptions decreased the undiscounted monetized impact of global anthropogenic mercury emissions in the corrected Trasande et al. model by $81 \%$ and decreased the estimated impact of U.S. sources by almost $97 \%$. When discounting is included, the U.S. EPA assumptions decreased the monetized estimate of global impacts by $88 \%$ and the impact of U.S. power plants by $98 \%$.

The choice of a linear model (i.e., a K-power model, with $K=1$ ) was based on the recommendation of the National Research Council (NRC 2000):

After extensive discussion, the committee concluded that the most reliable and defensible results for the purpose of risk assessment are those based on the K-power model.

Trasande et al. choose to emphasize the results of their logarithmic model, which produces their highest estimates of monetized impacts. We do not dispute that there may be cases in which a logarithmic model might be appropriate, but in the case of methylmercury, the NRC (2000) was unequivocal:

For $\mathrm{MeHg}$, the committee believes that a good argument can be made for the use of a K-power model with $\mathrm{K}$ constrained to be greater than or equal to 1 . That rules out square-root $(K=0.5)$ and $\log$ models (the limiting case as $\mathrm{K}$ approaches 0 ).
For the U.S. EPA dose-response slope, we used the results of an integrated statistical analysis by Ryan (2005), which has been recently updated (Axelrad et al. 2007). The analysis of Axelrad et al. includes results from the Seychelles study and also those of the Faroe Islands study (which was used by Trasande et al. 2005), as well as the New Zealand study. All three of these studies were used by the NRC (2000) and are described as being "well designed and carefully conducted, and each examined prenatal $\mathrm{MeHg}$ exposures within the range of the general U.S. population exposures." We will concede that controlling for maternal fish intake when assessing the impact of mercury on neurodevelopment is an important consideration that can be addressed in the future.

The assumption that, on average, $16 \%$ of the total mercury deposition in the United States is from American and Canadian sources comes straight from the U.S. EPA model used for the CAMR. As discussed in our article (Griffiths et al. 2007), the U.S. EPA used a spatially explicit air quality model to simulate the location of mercury deposition, but we used the average value to compare it to Trasande et al.'s (2005) assumption that $60 \%$ of the mercury content in all domestically caught fish is due to American sources. It is true that in the study of Steubenville, Ohio, published after the CAMR was promulgated, Keeler (2006) found a much higher percentage of local and regional deposition (70\% of the mercury wet deposition, not $80-90 \%)$, but this is an estimate of deposition at a single point and cannot be extrapolated to the entire country. Furthermore, the same U.S. EPA model that produced the $16 \%$ average value predicts comparatively high values for the Steubenville region of Ohio (U.S. EPA 2006).

With regard to the charge that we assumed there will be no reductions in fish contamination until after 15 years, Transande et al. are wrong. In our article (Griffiths et al. 2007) we are clear in our position that benefits build over time during the transition path from the current conditions to the new equilibrium. The choice of 15 years is an average period over which to discount the benefits, reflecting the 5-30 years for freshwater systems and the 30-200 years for ocean systems to reach equilibrium. Furthermore, we reported the undiscounted monetized results, which could be compared to Trasande et. al's (2005) implicit assumption of the instantaneous elimination of all anthropogenic mercury from the environment.

Finally, Trasande et al.'s reference to Viscusi and Aldy (2004) is truly baffling. 
That article is a review and evaluation of dozens of studies on the value of a statistical life (VSL). A VSL is derived from the tradeoffs witnessed in the market and elsewhere between income and small changes in risk of death. The value for a small change in mortality risk is aggregated to statistical lives in order to be comparable to risk assessment estimates. Because mortality risk and IQ decrements are vastly different items, there is no expected relationship between these two values.

The views expressed here are those of the authors and do not necessarily reflect those of the U.S. EPA.

The authors declare they have no competing financial interests.

\section{Charles Griffiths Al McGartland Maggie Miller}

National Center for Environmental Economics

U.S. Environmental Protection Agency Washington, DC E-mail: griffiths.charles@epa.gov

\section{REFERENCES}

Axelrad DA, Bellinger DC, Ryan LM, Woodruff TJ. 2007. Doseresponse relationship of prenatal mercury exposure and IQ: an integrative analysis of epidemiologic data. Environ Health Perspect 115:609-615.

Griffiths C, McGartland A, Miller M. 2007. A comparison of the monetized impact of 10 decrements from mercury emissions. Environ Health Perspect 115:841-847.

Keeler GJ, Landis MS, Norris GA, Christianson EM, Dvonch JT. 2006. Sources of mercury wet deposition in eastern Ohio, USA. Environ Sci Technol 40:5874-5881.

NRC (National Research Council). 2000. Toxicological Effects of Methylmercury. Washington, DC:National Academy Press.

Ryan LM. 2005. Effects of Prenatal Methylmercury on Childhood 10: A Synthesis of Three Studies. EPA-HOOAR-2002-0056-6048 and EPA-HQ-OAR-2002-0056-6049. Available: http://www.regulations.gov [accessed 20 January 2006].

Trasande L, Landrigan PJ, Schechter C. 2005. Public health and economic consequences of methyl mercury toxicity to the developing brain. Environ Health Perspect 113:590-596.

U.S. EPA. 2006. Revision of December 2000 Clean Air Act Section 112(n) Finding Regarding Electric Utility Steam Generating Units; and Standards of Performance for New and Existing Electric Utility Steam Generating Units: Reconsideration. Fed Reg 71:33388-33402.

Viscusi WK, Aldy JE. 2004. The Value of a Statistical Life: A Critical Review of Market Estimates Throughout the World. NBER Working Paper 9487. Available: http://www.nber.org/ papers/w9487 [accessed 9 July 2004].

\section{Environmental Exposures and ADHD}

\section{doi: 10.1289/ehp.10274}

In their article, "Exposures to Environmental Toxicants and Attention Deficit Hyperactivity Disorder [ADHD] in U.S. Children," Braun et al. (2006) advanced our knowledge of the effects of environmental tobacco smoke (ETS) and lead on the central nervous system of children. With respect to lead exposure, the study, importantly, focused on an older age group (4-15 years) than is generally studied ( $<6$ years) because of the greater sensitivity of the developing central nervous system to environmental insult early in life [Centers for Disease Control and Prevention (CDC) 1997].

In the logistic model used by Braun et al. (2006), the association of ADHD with lead exposure was statistically significant in the highest exposure quintile; however, it was also tenuous. Although not unheard of, the cutoff $(p<0.2)$ for inclusion of factors and variables associated with ADHD on univariate analysis was generous compared with the commonly used 0.1 or 0.05 , and very close to the $p$-value of the lead-ADHD association of 0.19 . The lead-ADHD relationship also exhibited a significant monotonic dose response, so it would have been helpful to know how the authors developed their exposure metric. Why, for example, were quintiles selected rather than another interval scheme, and why were they not of uniform size? Was the reported dose response the only model considered, or did the authors investigate other models, as some have done in studying the relationship of lead exposure and cognition (Canfield et al. 2003)?

Braun et al. (2006) noted that their analyses were limited by the cross-sectional nature of the National Health and Nutrition Examination Survey data they used, precluding adjustment of their model for certain covariates and potential confounders (e.g., parental psychopathology). Based on data from multiple studies, ADHD heritability has been estimated to be about $75 \%$ (Biederman and Faraone 2005). Inability to adjust for parental psychopathology is therefore an important limitation, because adjustment would likely reduce-and might eliminate-the associations of ADHD with ETS and lead. In studies of lead exposure and cognition, some of which Braun et al. (2006) cited as being consistent with their findings, the strength of the IQ-lead relationship can be dwarfed by the relationship of IQ to other factors such as parenting and socioeconomic status (Koller et al. 2004). When reporting associations of environmental contaminants and pathology, it seems prudent to maintain a broader perspective, as well as an environmental health perspective.

The author declares he has no competing financial interests.

Jack Brondum Hennepin County Department of Human Services and Public Health Environmental Health and Epidemiology Hopkins, Minnesota E-mail: jack.brondum@co.hennepin.mn.us

\section{REFERENCES}

Biederman J, Faraone SV. 2005. Attention-deficit hyperactivity disorder. Lancet 366:237-248.

Braun JM, Kahn RS, Froehlich T, Auinger P, Lanphear BP 2006. Exposures to environmental toxicants and attention deficit hyperactivity disorder in U.S. children. Environ Health Perspect 114:1904-1909.

Canfield RL, Henderson CR Jr, Cory-Schlechta DA, Cox C, Jusko TA, Lanphear BP. 2003. Intellectual impairment in children with blood lead concentrations below $10 \mu \mathrm{g}$ per deciliter. N Engl J Med 348:1517-1526.

CDC. 1997. Screening Young Children for Lead Poisoning: Guidance for State and Local Public Health Officials. Atlanta, GA:Centers for Disease Control and Prevention.

Koller K, Brown T, Spurgeon, Levy L. 2004. Recent developments in low-level lead exposure and intellectual impairment in children. Environ Health Perspect 112:987-994.

\section{Lead and Neuroprotection by Iron in ADHD}

doi: 10.1289/ehp.10304

We read with special interest the article by Braun et al. (2006). In this large survey, the authors concluded that prenatal exposure to tobacco and environmental lead are risk factors for attention deficit hyperactivity disorder (ADHD).

We would like to focus on the potential neuroprotective role of iron against the deleterious effect of lead on the development of ADHD symptoms.

Although the mechanisms underlying ADHD remain unclear, both genetic and environmental factors have been implicated. In a recent review on the implication of the dopaminergic system in the etiology of ADHD, Swanson et al. (2007) highlighted the importance of environmental risk factors as possible etiologies of dopamine deficit. Among these environmental factors, Swanson et al. (2007) cited the effects of lead exposure (at levels $<10 \mu \mathrm{g} / \mathrm{dL}$ ) on ADHDrelated behaviors and ADHD diagnosis.

Lead in the central nervous system may contribute to dopaminergic dysfunction inducing alteration of dopamine release and dopamine receptor density (Gedeon et al. 2001; Lidsky et al. 2003). Moreover, lead may disrupt the structure of the blood-brain barrier function essential for brain integrity (Dyatlov et al. 1998). Interestingly, Wang et al. (2007) recently reported that iron supplementation protects the integrity of the blood-brain barrier against lead insults. On the other hand, iron deficiency could increase the toxic effect of lead, suggesting a potent neuroprotective effect of iron supplementation on dopaminergic dysfunction due to lead exposure (Wright 1999; Wright et al. 2003)

In a controlled comparison group study, we (Konofal et al. 2004) showed that iron deficiency was correlated to ADHD symptoms severity, hypothesizing that iron supplementation may improve symptoms of 
ADHD in those subjects with low ferritin levels.

Given that lead exposure may contribute to ADHD and iron deficiency may exacerbate deleterious effects caused by lead, we recommend systematically seeking for iron deficiency in children with ADHD. We also think that controlled studies assessing the potential effectiveness of iron supplementation on ADHD symptoms should be encouraged. Such studies could aid the understanding of the complex pathophysiology underlying ADHD and provide effective therapeutic strategies for this disorder.

The authors declare they have no competing financial interests.

Eric Konofal Samuele Cortese Child Psychopathology Unit University Hospital Robert Debré Paris, France E-mail: eric.konofal@rdb.aphp.fr

\section{REFERENCES}

Braun JM, Kahn RS, Froehlich T, Auinger P, Lanphear BP. 2006. Exposures to environmental toxicants and attention deficit hyperactivity disorder in U.S. children. Environ Health Perspect 114:1904-1909.

Dyatlov VA, Platoshin AV, Lawrence DA, Carpenter DO. 1998. Lead potentiates cytokine- and glutamate-mediated increases in permeability of the blood-brain barrier. Neurotoxicology 19:283-291.

Gedeon Y, Ramesh GT, Wellman PJ, Jadhav AL. 2001. Changes in mesocorticolimbic dopamine and D1/D2 receptor levels after low level lead exposure: a time course study. Toxicol Lett 123(2-3):217-226.

Konofal E, Lecendreux M, Arnulf I, Mouren MC. 2004. Iron deficiency in children with attention-deficit/hyperactivity disorder. Arch Pediatr Adolesc Med 158(12):1113-1115.

Lidsky TI, Schneider JS. 2003. Lead neurotoxicity in children: basic mechanisms and clinical correlates. Brain 126:5-19.

Swanson JM, Kinsbourne M, Nigg J, Lanphear B, Stefanatos GA, Volkow N, et al. 2007. Etiologic subtypes of attentiondeficit/hyperactivity disorder: brain imaging, molecular genetic and environmental factors and the dopamine hypothesis. Neuropsychol Rev 17(1):39-59.

Wang Q, Luo W, Zheng W, Liu Y, Xu H, Zheng G, et al. 2007. Iron supplement prevents lead-induced disruption of the blood-brain barrier during rat development. Toxicol Appl Pharmacol 219(1):33-41.

Wright R0. 1999. The role of iron therapy in childhood plumbism. Curr Opin Pediatr 11(3):255-258.

Wright RO, Tsaih SW, Schwartz J, Wright RJ, Hu H. 2003. Association between iron deficiency and blood lead level in a longitudinal analysis of children followed in an urban primary care clinic. J Pediatrics 142(1):9-14.

\section{ADHD: Braun et al. Respond}

\section{doi: 10.1289/ehp.10274R}

We appreciate the comments of Brondum, and Konofal and Cortese, and the opportunity to clarify our results (Braun et al. 2006). It is common practice to select variables with a $p$-value of 0.2 for inclusion in multivariable models (Katz 1999). Although the association of blood lead levels and ADHD appeared "tenuous" in bivariate analysis (i.e., $p=0.19$ ), this was largely an artifact of our decision to categorize blood lead levels. When we entered lead into our multivariable analysis as a continuous variable, we found a 1.2 -fold increased odds [95\% confidence interval $(\mathrm{CI})$, $1.0-1.4 ; p=0.02]$ of ADHD for each $1.0-\mu \mathrm{g} / \mathrm{dL}$ increase in blood lead levels. The blood lead quintiles were not divided into exactly equal sample sizes because we used weighted percentages to categorize the data. We decided a priori to present the analysis in quintiles to make the results easier to interpret and also to illustrate any dose-response relationships for blood lead levels and ADHD.

As we noted in the "Discussion" of our article (Braun et al. 2006), a limitation of our study was the inability to adjust for parental psychopathology. This is an unfortunate trade-off when using a large nationally representative survey. In other studies, prenatal tobacco exposure has been shown to be a risk factor for the development of ADHD after controlling for parental psychopathology (Mick et al. 2002; Weissman et al. 1999). Although there is considerable experimental and epidemiologic evidence linking lead exposure with behaviors consistent with ADHD, future studies of childhood lead exposure will need to confirm our results by accounting for parental psychopathology and other potential confounders.

The hypothesis proposed by Konofal and Cortese - that iron deficiency may play a role in symptom severity among children with ADHD - is intriguing. Indeed, it was their original research that prompted us to incorporate ferritin as a measure of iron status (Konofal et al. 2004). It is certainly plausible that iron deficiency may confound or modify the effects of environmental lead exposure on ADHD in children. Alternatively, lead exposure may act as a confounder or modifier for the observed effects of iron deficiency with ADHD. Unfortunately, we were not able to examine whether ferritin (or other indicators of iron status) was associated with ADHD symptom severity using the National Health and Nutrition Examination Survey. Nor did we specifically test for an association between iron deficiency and ADHD. Although iron or other micronutrient supplementation may protect children from lead toxicity, recent evidence from a double-blind randomized trial (Kordas et al. 2005) suggests that iron and zinc supplementation did not appreciably lower blood lead levels or improve child behavior, as measured by the Conners Rating Scales. However, Kordas et al. included only children without anemia in their trial.

The authors declare they have no competing financial interests.

Joe M. Braun

Department of Epidemiology

University of North Carolina-Chapel Hill Chapel Hill, North Carolina E-mail: jmbraun@unc.edu

Bruce P. Lanphear Robert S. Kahn

Tanya Froehlich

Department of Pediatrics Cincinnati Children's Hospital Medical Center

Cincinnati, Ohio

E-mail: bruce.lanphear@chmcc.org

Peggy Auinger

Department of Pediatrics

University of Rochester School of Medicine Rochester, New York

\section{REFERENCES}

Braun JM, Froehlich TF, Kahn RS, Auinger P, Lanphear BP. 2006. Exposures to environmental toxicants and attention deficit hyperactivity disorder in U.S. children. Environ Health Perspect 114:1904-1909.

Katz M. 1999. Multivariable Analysis: A Practical Guide for Clinicians. New York:Cambridge University Press.

Konofal E, Lecendreux M, Arnulf I, Mouren M. 2004. Iron deficiency in children with attention-deficit/hyperactivity disorder. Arch Pediatr Adolesc Med 158:1113-1115.

Kordas K, Stoltzfus RJ, Lopez P, Rico JA, Rosado JL. 2005. Iron and zinc supplementation does not improve parent or teacher ratings of behavior in first grade Mexican children exposed to lead. J Pediatr 147:632-639.

Mick E, Biederman J, Faraone SV, Sayer J, Kleinman S. 2002. Case-control study of attention-deficit hyperactivity disorder and maternal smoking, alcohol use, and drug use during pregnancy. J Am Acad Child Adolesc Psychiatry 41:378-385.

Weissman MM, Warner V, Wickramaratne PJ, Kandel DB. 1999. Maternal smoking during pregnancy and psychopathology in offspring followed to adulthood. J Am Acad Child Adolesc Psychiatry 38:892-899.

\section{ERRATUM}

In the article by O'Neil [Environ Health Perspect 115:1087-1093 (2007)], the corresponding author's address is incorrect. The correct address is S.G. O'Neil, 1071 Blue Hill Ave., Milton, MA 02186. Telephone: 617-333-0500. E-mail: soneil0905@curry.edu

EHP regrets the error. 